\title{
"MEDÔ MEDO": INVESTIGAÇÃO SOBRE A FOBIA EM FREUD, LACAN E AUTORES CONTEMPORÂNEOS A PARTIR DE UM CASO CLÍNICO
}

André Ehrlich e Vinicius Anciaes Darriba

\author{
André Ehrlich \\ Graduado em \\ Psicologia pela \\ Universidade \\ Federal do Paraná \\ e membro da \\ Biblioteca Freudiana \\ de Curitiba. \\ Vinicius Anciaes Darriba \\ Professor adjunto \\ do Instituto \\ de Psicologia/ \\ Programa de \\ Pós-Graduação \\ em Psicanálise da \\ Universidade do \\ Estado do Rio de \\ Janeiro (Uerj).
}

RESUMO: A partir de um caso clínico emerge a seguinte questão: a fobia deve ser considerada uma entidade clínica ou uma figura clínica a se presentificar em contextos diversos? O presente artigo investiga o item nas obras de Freud, Lacan e de dois autores da atualidade: Ricardo Diaz Romero e Charles Melman, que reacendem o debate em torno do tema. A psicanálise, como constructo teórico que surge a partir da escuta clínica de Freud, somente mantém seu sentido no que continua a nos possibilitar tratar o real da clínica pelo simbólico. Neste sentido é que, efetuado um percurso teórico, retornamos, ao final do artigo, à experiência clínica.

Palavras-chave: Fobia, sintoma, castração, entidade clínica, estrutura.

ABSTRACT: Fear fear: an investigation about phobia in Freud, Lacan and other contemporary authors (Diaz Romero and Charles Melman) based on a clinical case. A question emerges based on a clinical case: should phobia be considered a clinical entity or a clinical figure to make itself present in various contexts? The present article investigates this matter in the works of Freud, Lacan and two current authors that reignite the debate around the theme. Psychoanalysis, as a theoretical body to emerge from Freud's clinical listening, only maintains its reason of being in which it still makes possible for us to handle the real in clinical experience through the symbolic. It is in this sense that, trailing a theoretical path, we return to the clinical experience at the end of the article.

Keywords: Phobia, symptom, castration, clinical entity, structure. 
A ssumir a psicanálise como uma práxis implica buscar elementos que nos possibilitem tratar o real da clínica pelo simbólico. Ou seja, a pesquisa em psicanálise nasce da experiência clínica e a ela retorna perpassada pelos conceitos que nos guiam. No caso clínico que suscitou a presente pesquisa, o paciente, cujo diagnóstico parecia inicialmente apontar para uma neurose obsessiva, desenvolve intensa fobia. O relato deste paciente em relação ao seu objeto fóbico é marcado por enunciados duros, monolíticos, imutáveis. Nestas ocasiões, qualquer tentativa de engajá-lo em processo de associação livre resultava na repetição do enunciado de seu relato como um todo em intensa angústia. Em determinada sessão o paciente trouxe um poema de sua autoria, que tinha por refrão o verso "medo, medo, medo, medo". Com o intuito de implicar o paciente em seu sintoma, o analista intervêm: "Medô, medo?"

É sabido que Freud, já em 1895, nos diz que, em geral, os rituais obsessivos se constituem sobre um fundo fóbico, mas a dureza do discurso do paciente, assim como o fato de a fobia vir a intensificar alguns sintomas já presentes remeteu à seguinte questão: podemos considerar a fobia uma entidade clínica? Escolhemos nos aprofundar nesta questão, iniciando pela investigação e discussão das elaborações de Freud com respeito à fobia. Nelas podemos destacar três momentos distintos: um primeiro momento, anterior ao caso "pequeno Hans”; um segundo, como resultado direto do tratamento de Hans; e um terceiro momento, marcado pela reelaboração de Freud concernente à angústia, apresentada em seu texto "Inibição, sintoma e angústia” (1926).

Em seguida, nos debruçaremos sobre as elaborações de Lacan, que, em seu seminário de 1956-57, abordou extensamente o caso “pequeno Hans", revisitando-o ainda no seminário de 1968-69. Completando o âmbito teórico de nossa investigação, dirigiremos nossa atenção às contribuições de autores que, na trilha de Lacan, reacendem o debate em torno da questão do artigo — o estatuto a ser gozado pela fobia. Trabalharemos, particularmente, com as elaborações de Ricardo Diaz Romero (1997) e Charles Melman (1994). O retorno ao citado caso clínico nos propiciará, então, um diálogo entre as elaborações teóricas e o real da clínica.

Na medida em que colocamos a pergunta se a fobia pode ser tomada como uma entidade clínica, ou em termos lacanianos, visto seguirmos nesta direção, se há uma estrutura fóbica, é preciso ter em conta a problemática do diagnóstico na psicanálise. Em sua particularidade, ele não é baseado na sintomatologia. Portanto, não devemos confundi-lo com o que é listado na Classificação Estatística Internacional de Doenças e Problemas Relacionados com a Saúde (CID-10) entre F 40.0 e F 40.2. Para a psicanálise, o decisivo para o estabelecimento de um diagnóstico é o que o discurso do paciente revela da economia do desejo. 
Pensar o diagnóstico para a psicanálise é colocá-lo, já nos termos de Lacan, na ordem de uma estrutura.

Para Lacan (1957-58), “não há definição possível do campo analítico sem que se estabeleça a função estruturante do significante em relação ao sujeito, seu valor constitutivo no sujeito como falante" (LACAN, 1957-58/1999, p.526). Deste modo, o simbólico, campo do significante, como estrutura, é exterior ao homem, maior que ele e o antecede. Da perspectiva do sujeito, a questão que se coloca é seu modo estrutural de relação com a totalidade da linguagem, ou seja, seu modo singular de submissão ao simbólico. Considerando, como o faz Lacan, o complexo de Édipo como processo de simbolização por excelência, questionar a estrutura do sujeito é primordialmente investigar as consequências que podem ser atribuídas a acidentes nesse processo.

Quando falamos de estrutura supomos certa estabilidade. Nas palavras de Joel Dor: "São semelhantes trajetórias estabilizadas, que chamarei, por assim dizer, traços estruturais. As referências diagnósticas estruturais aparecem, então, como indícios codificados pelos traços da estrutura que são, eles próprios, testemunhas da economia do desejo" (DOR, 1994, p.22).

Em relação à clínica, a estrutura nos aponta uma direção do tratamento, entre outras coisas, por também nos guiar no sentido das saídas possíveis para o sujeito, suas distintas possibilidades de cura.

\section{A FOBIA EM FREUD}

É em seu artigo "Psiconeuroses de defesa” (1894/1987) que Freud empreende uma primeira aproximação ao mecanismo psíquico na formação das fobias. Neste artigo, histeria, fobias e obsessões são descritas como afecções cujos mecanismos passam a divergir somente após o recalcamento de uma representação. A histeria seria caracterizada pela capacidade de conversão, enquanto que na neurose obsessiva e nas fobias, teríamos um mecanismo de "transposição" (que mais tarde receberá o nome de “deslocamento”). No entanto, Freud abre duas exceções: a das fobias vinculadas à histeria e a das “fobias típicas”, cujo modelo é a agorafobia e para a qual não haveria nenhuma representação recalcada.

Já no ano seguinte, no artigo “Obsessões e fobias”, Freud (1895/1987, p.82) declara: "O mecanismo das fobias é totalmente diferente do das obsessões. A substituição não é mais o traço predominante nas primeiras; a análise psicológica não revela nelas nenhuma representação incompatível substituída.” Assim sendo, as fobias passam a fazer parte da neurose de angústia, ou melhor, são uma manifestação psíquica da neurose de angústia. 
"A neurose de angústia tem uma origem sexual, mas não se prende a representações extraídas da vida sexual; para dizê-lo com propriedade, não tem qualquer mecanismo psíquico. Sua causa específica é a acumulação de tensão sexual produzida pela abstinência ou pela excitação sexual não consumada.” (FREUD, 1895/1987, p.83)

A classificação empreendida em "Psiconeuroses de defesa” é confirmada e elaborada mais longamente no artigo "Sobre os fundamentos para destacar da neurastenia uma síndrome especifica denominada 'neurose de angústia”, também de 1895. Deste modo, temos as fobias de origem traumática, ligadas à histeria; as fobias atípicas, que se baseiam nas obsessões e gozam do mesmo mecanismo psíquico destas; e as fobias típicas, vinculadas à neurose de angústia, para as quais Freud não encontra um mecanismo psíquico.

Nesta época, Freud ainda perseguia o objetivo de fornecer uma base neurológica aos fenômenos psíquicos, e isto transparece claramente em sua descrição quanto à origem da neurose de angústia. Por outro lado, é pela escuta das histéricas que Freud adentra a tentativa de elucidação dos mecanismos psíquicos. É neste contexto que compreendemos a declaração: "Quando se penetra no mecanismo das duas neuroses (histeria e neurose de angústia) [...] vem à tona certos aspectos que sugerem que a neurose de angústia é, realmente, o equivalente somático da histeria” (FREUD, 1895/1987, p.111).

Neste inicio das elaborações freudianas, as fobias revelam-se como síndromes que resistem a uma classificação quanto ao seu mecanismo psíquico. Suas características permitem a Freud situá-las ora entre as neuroses de transferência (histeria e neurose obsessiva) ora entre as neuroses atuais. Esta característica das fobias de comparecerem em diversas entidades clínicas é pouco a pouco colocada em segundo plano por Freud a partir do caso 'pequeno Hans'.

O relato clínico deste célebre caso não foi elaborado por Freud, mas pelo pai de Hans. É certo que a análise do pequeno Hans foi orientada por Freud, mas é o pai de Hans que a conduz, submetendo suas notas à avaliação do pai da psicanálise. Freud se encontra com o pequeno paciente apenas uma vez.

Hans vem a desenvolver uma fobia de cavalos, ou melhor, de ser mordido por um deles. Para Freud:

\footnotetext{
"Esta angústia correspondente ao anseio recalcado é inicialmente como toda angústia infantil, sem objeto; é ainda angústia (Angst) e não medo (Furcht). A criança [inicialmente] não consegue saber do que tem medo e quando Hans, em seu primeiro passeio com a babá, não quer dizer o que teme, é porque ele simplesmente não sabe.” (FREUD, 1909/1989, p 28, tradução nossa).
} 
Freud não nos diz por que a angústia precisa achar um objeto, mas com base na concepção dos processos psíquicos que tinha em 1909, podemos especular que a razão seja econômica, pois ao processo de pensamento corresponde uma diminuição na quantidade de excitação psíquica. Lembrando que o princípio do prazer procura sempre manter esta excitação a um nível mínimo, ligar a angústia a uma representação seguiria este princípio.

Quanto à procedência dos elementos para a eleição do objeto fóbico, Freud nos responde: “É provável que dos complexos — até aqui desconhecidos por nós - que contribuíram para o recalque e mantiveram sob recalque os sentimentos libidinais de Hans para com sua mãe" (FREUD, 1909/1989, p.37, tradução nossa). Evidentemente o cavalo é um objeto fobígeno multideterminado. Podemos afirmar, como primeira determinação, que a queda de um cavalo ao puxar uma carroça tem, para Hans, uma relação com o parto, a chegada de sua irmãzinha. Outra determinação encontramos no já demonstrado interesse de Hans por cavalos no contexto de sua curiosidade pelos “faz-pipi”, em especial o dos grandes animais.

Adiante, Freud explicita que a geração da angústia vem do recalque, que é a libido recalcada que retorna como angústia. Este posicionamento teórico, expresso pela primeira vez em 1895, irá perdurar até 1926.

Retornando à questão central que nos move, ao final da discussão sobre o caso do "pequeno Hans”, Freud cunha o termo "histeria de angústia”:

“Parece certo que elas (as fobias) só devam ser encaradas como síndromes, que podem formar parte de várias neuroses e que não precisamos classificá-las como processos patológicos independentes. Para fobias da espécie a que pertence a do pequeno Hans, e que são, na realidade, as mais comuns, o nome de 'histeria de angústia’ não parece inapropriado. [...] O termo se justifica pela concordância no mecanismo psicológico desta fobia com a histeria exceto por um único ponto, mas decisivo para a diferenciação. A libido liberada do material patogênico através do recalque não é convertida do psíquico para uma inervação somática, mas sim liberada como angústia.” (FREUD, 1909/1989, p.99, tradução nossa).

Nos próximos anos, Freud retoma repetidas vezes a temática da fobia. Deste modo, em “Introdução ao narcisismo” de 1914, podemos ler: “A angústia, nas neuroses de transferência, pode ser substituída por elaborações psíquicas ulteriores, ou seja, por conversão, construção reativa e construção de proteção (Schutzbildung) (nas fobias)" (FREUD, 1914/1989, p.53, tradução nossa). Esta frase denuncia uma mudança de posição em relação a dois aspectos. Primeiro, as fobias passam a estar claramente situadas entre as neuroses de transferência, ou para sermos mais precisos, a histeria de angústia passa a ser a terceira forma de neurose 
de transferência. Segundo, a substituição da angústia livremente flutuante por outra coisa passa a ser uma característica comum às neuroses de transferência e não mais privilégio da histeria de angústia. Assim, se por um lado as fobias, como síndrome, podem se fazer presentes em todas as entidades clínicas, por outro a histeria de angústia passa a ocupar um lugar independente da histeria de conversão, com um mecanismo próprio de defesa contra a angústia. Vale esclarecer que a fobia, para Freud, é a série de evitações ao objeto fóbico.

Em sua Conferência 25 (A angústia), de 1917, Freud diferencia de maneira clara a neurose de angústia, na qual temos uma angústia flutuante, sem objeto, da histeria de angústia. Uma não seria um degrau mais elevado da outra, comparecendo juntas apenas em casos excepcionais. Além disso, Freud declara que as fobias, em sua totalidade, devem ser ordenadas à histeria de angústia. Freud, portanto, revisa sua posição expressa em 1895 e também em 1909. Se oito anos antes, as fobias poderiam comparecer em diversas afecções neuróticas (neuróticas no sentido freudiano do termo), aqui temos praticamente uma coincidência entre a síndrome fóbica e a afecção histeria de angústia.

Em 1926, com “Inibição, sintoma e angústia”, Freud reformula sua teoria sobre a angústia. Podemos resumir as mudanças no pensamento de Freud ao dizermos que a) a partir deste trabalho a angústia não é mais resultante de uma transformação direta da libido vinculada a uma representação recalcada; b) não é o recalque que provoca a angústia, mas sim a angústia que leva ao recalque; c) sua sede não está mais no Isso, mas no Eu; e d) em última instância, toda angústia está vinculada a um perigo real.

Neste texto, Freud passa a fazer uso da diferenciação entre "angústia como sinal” e "angústia automática”. A angústia automática se justifica quando o sujeito experimenta uma situação de desamparo psíquico, a angústia como sinal é produzida pelo Eu quando há ameaça de tal situação de desamparo. A partir da angústia original, surgida na separação do bebê de sua mãe, Freud traça uma sequência de transformações geradoras de angústia e conclui: “A condição de angústia da perda de amor tem na histeria papel semelhante à ameaça de castração nas fobias e à angústia do Supereu na neurose obsessiva” (FREUD, 1926/1989, p.283, tradução nossa).

Com a mudança de posição de Freud em relação à angústia, efetuada em “Inibição, sintoma e angústia” (1926), temos não apenas a confirmação que o recalque seja um mecanismo de proteção diante da angústia como, considerando a série exposta no parágrafo anterior (vinculando a fobia à angústia de castração) e o apêndice do mesmo texto no qual Freud diferencia as formações reativas do recalque, a colocação, ao menos indiretamente, da eleição de um objeto fóbico em patamar semelhante aos dois mecanismos de defesa já citados. 
Um último ponto a se observar é que Freud deixa claro em sua conferência "Angústia e vida pulsional” (1933) que a angústia de castração não teria lugar nas mulheres. Isto levanta a seguinte questão: haveria uma relação privilegiada do sexo masculino com as fobias? Retornaremos a esta questão ao abordarmos a concepção lacaniana com respeito às fobias.

O essencial em relação à questão do artigo é, ao final das elaborações freudianas, a histeria de angústia englobar a quase totalidade das fobias. A entidade clínica seria, portanto, a histeria de angústia, em cujo contexto se presentificaria a fobia. Sendo tal entidade clínica um dos modos de retorno do recalcado, concluímos que, para Freud, a fobia, abarcada pela histeria de angústia, figura no âmbito das neuroses de transferência.

\section{A FOBIA EM LACAN}

Em seu seminário proferido em 1956-57 (O Seminário, livro 4) Lacan, ao elaborar a "relação de objeto", revisita o caso do "pequeno Hans" e formula uma teorização para a fobia. Se, para Freud, a angústia de castração à qual remete a fobia denota uma presença excessiva do pai como agente castrador na fantasia da criança, Lacan, pelo contrário, concebe a fobia como sendo da ordem de um apelo por socorro diante de uma insuficiência paterna.

A chave para entendermos a conceituação de Lacan quanto à fobia está nas últimas elaborações de Freud com respeito à feminilidade. Nestes textos, Freud coloca que uma das maneiras do sujeito feminino aceder à feminilidade é pela equação simbólica falo-bebê. Ou seja, a maternidade torna-se uma das possíveis vicissitudes da relação da mulher com a falta fálica e, neste sentido, a criança vem ao mundo para fantasisticamente preencher esta falta da mãe. Nas palavras de Miller: "a tese fundamental apresentada por Lacan, nesse Seminário" consiste em "que o determinante para cada sujeito é a relação da mulher que se encontra como sua mãe, a relação dessa mulher com a própria falta” (MILLER, 1993, p.63).

A relação pré-edipiana mãe-criança é conceituada por Lacan em termos de uma tríade imaginária. Ou seja, na relação da criança com a mãe, o falo já se encontra inserido. Esta é abalada a partir do que Lacan (1957) denomina “decepção fundamental da criança”, quando ela reconhece que não é o objeto único da mãe, mas que o objeto de desejo da mãe é o falo. Ao perceber que a mãe também é privada deste objeto, temos um momento crítico, angustiante, pois diante deste furo da imagem da mãe a criança está sob a ameaça de se tornar cativa das significações maternas. A saída normatizante, que aponta para a neurose, se dá com a entrada da função do pai nesta triangulação mãe / criança / falo, como 
quarto elemento: o pai como possuidor do falo, aquele que possibilita que a falta do falo assuma seu lugar na ordem simbólica.

Nas palavras de Lacan: "Por ocasião de um momento particularmente crítico, quando nenhuma via de outra natureza está aberta para a solução do problema, a fobia constitui um apelo por socorro, o apelo a um elemento simbólico singular” (LACAN, 1956-57/1995, p.57). Ou seja, diante de uma insuficiência da função paterna, o objeto fóbico, como elemento simbólico singular, vem exercer a função de complementação com relação a um furo na realidade.

Deste modo, Lacan mantém a relação estabelecida por Freud entre a angústia de castração e a fobia, mas a castração em jogo é a castração da mãe. Este posicionamento vem resolver a questão que colocamos em relação às elaborações de Freud quanto à fobia ter uma relação privilegiada com o sexo masculino tornando a angústia de castração unissex.

Quanto à função paterna, tão mencionada acima, trata-se do pai real. É este que tem como função transmitir à criança seu lugar na ordem simbólica. É também neste sentido que ele castra a criança, pois é na ordem simbólica que temos a incidência da falta como tal.

Voltando nossa atenção para a eleição do objeto fóbico, Lacan (1956-57/1995, p.392) o denomina "primeiro cristal de uma cristalização organizada entre o simbólico e o real", um significante em torno do qual, no caso do "pequeno Hans", vem se expandir o desenvolvimento mítico em que consiste sua análise. Vemos aí uma direção de cura, pois a proliferação mítica se caracteriza pela "utilização de elementos imaginários para o esgotamento de certo exercício da troca simbólica. Isso é que vai acabar por tornar inútil este elemento de limiar, isto é de primeira estruturação simbólica da realidade, que é sua fobia” (LACAN, 195657/1995, p.290). O objeto fóbico, como significante, irá servir de suporte para o remanejamento do significado. Finda uma serie de permutações do significante, é de se esperar que o significado saia, ao final, diferente do que era no início. Ao mesmo tempo, o caráter simbólico do significante mantém o significado potencialmente aberto. Colocar o sujeito no nível da questão é sua inserção na neurose. No fundo, não é o que esperamos de todo tratamento analítico?

Neste seminário de 1956-57, Lacan retorna repetidas vezes às últimas duas fantasias do “pequeno Hans”. Em sua penúltima fantasia, Hans casa seu pai com a avó e passa a desejar ter crianças imaginárias com a mãe. É uma solução atípica para o complexo de Édipo e que não o leva a se referenciar à função paterna, isto é, “que ele próprio aceda um dia a esta posição tão problemática e paradoxal de ser um pai” (LACAN, 1956-57/1995, p.208). Para Freud, a última fantasia, na qual o instalador de banheiras troca o popô de Hans por um maior, expressa um desejo vitorioso que supera sua angústia de castração. Já para Lacan, esta fantasia expressa que Hans, em nenhum momento tem que perder seu pênis: "Não há 
nenhuma fase de simbolização do pênis. [...] O que se produz não lhe permite integrar sua masculinidade por nenhum mecanismo a não ser a formação da identificação com o falo materno, que é igualmente de uma ordem distinta da do supereu" (LACAN, 1956-57/1995, p.429). Que o precipitado do complexo de Édipo, em Hans, venha a ser de ordem distinta do supereu não deixa de constituir um problema de ordem estrutural ao fim de seu tratamento.

Como uma primeira formulação quanto ao estatuto das fobias em Lacan, podemos situar estas como uma solução provisória que possibilita uma passagem do "instante de olhar" ao "tempo de compreender". Vale aqui situar que "instante de olhar", “tempo de compreender" e "momento de concluir" são as três escansões do tempo lógico propostas por Lacan em 1945. Deste modo, o objeto fóbico passa da imaginarização a algum grau de simbolização que permite preencher o mundo do fóbico de significações.

Uma formulação de caráter mais conclusivo virá somente em 1969, ocasião em que Lacan mais uma vez retoma o caso do "pequeno Hans":

“A fobia não deve ser vista, de modo algum, como uma entidade clínica, mas sim como uma placa giratória. Ela gira mais comumente para as duas grandes ordens da neurose, a histeria e a neurose obsessiva, e também realiza a junção com a estrutura perversa [...] Ela é muito menos uma entidade clínica isolável do que uma figura clinicamente ilustrada, de maneira espetacular, sem dúvida, mas em contextos infinitamente diversos." (LACAN, 1968-69/2008, p.298)

Quais seriam os critérios para se designar uma estrutura, uma entidade clínica isolável? Freud não fala em termos de estrutura, mas podemos afirmar que um dos paradigmas por ele utilizado para sua classificação das neuroses (no sentido freudiano do termo) é a transferência. Como vimos, Freud, ao final de sua obra, conclui que a quase todos os casos de fobia seriam inseríveis entre as neuroses de transferência, isoláveis sob a denominação de histeria de angústia.

Outro paradigma, este colocado por Lacan, mas se referindo diretamente aos ensinamentos de Freud: as modalidades de defesa diante da angústia de castração. O psicótico, em sua relação com a castração, foraclui, o perverso denega, o neurótico recalca. Quanto à fobia, esta é caracterizada por uma evitação da castração diante da carência do pai real. Esta modalidade de defesa é insinuada por Lacan em relação ao 'pequeno Hans'. Ele designa a saída de Hans de seu episódio fóbico como atípica e marcada pela carência paterna. Esta saída pode vir a moldar a relação do sujeito ao seu desejo? Em caso afirmativo, isto autorizaria a elevar a fobia ao status de uma estrutura. Se Lacan enfatiza, no entanto, não se tratar de uma entidade clínica isolável, nos encontraríamos frente a uma contradição ao conceber uma evitação da castração como modalidade de defesa 
própria da fobia. Todavia, tal evitação da castração pode também ser interpretada tão somente como um modo de manter a questão da castração em suspenso. Neste caso, a fobia não gozaria, em termos lógicos, da estabilidade necessária para ser designada como estrutura. Reportando-se a outros elementos da obra lacaniana, os autores que examinaremos a seguir argumentam por um estatuto estrutural para a fobia.

\section{OUTRAS EXPERIÊNCIAS CLÍNICAS QUANTO Ȧ FOBIA}

Quando falamos de psicanálise, estamos falando, em primeiro plano, de uma prática submetida a uma ética. As tentativas, a partir de Freud, de sistematizar o conhecimento advindo desta prática, da escuta na clínica, resultam em corpo teórico. Se considerarmos que uma teoria, como modelo explicativo, sempre representará, em alguma medida, uma redução do real de seu objeto, podemos concluir que o real da clínica será sempre maior que a elaboração teórica dela resultante. Deste modo, a clínica, como experiência viva, não só renova a teoria, como é prenhe da possibilidade de vir a refutá-la. Uma elaboração teórica deve sempre ser vista como um modelo provisório.

A reflexão acima exposta não só autoriza como justifica a extensão de nossa pesquisa para alguns autores que, apesar de se posicionarem claramente como adeptos dos ensinamentos de Lacan, foram levados por suas experiências clínicas a elaborações não coincidentes, como veremos, quanto ao mestre no que se refere à fobia.Ricardo Diaz Romero trabalha com a hipótese de ao menos duas experiências clínicas distintas em relação à fobia: "haveria fobias que são sintomas de crise ou momentos constitutivos em outras estruturas e, por outra parte, haveria outras fobias das quais se poderia dizer que constituem uma estrutura diferencial” (DIAZ ROMERO, 1997, p.57). Nas primeiras, em concordância com Lacan, o objeto fóbico é posto em função de significante e a fobia constitui uma saída provisória diante da não passagem do "instante de olhar" para o "tempo de compreender". Nestas, chega-se ao "momento de concluir" pela via do significante. No segundo grupo, o objeto fóbico não possibilitaria a passagem ao “tempo de compreender”, ou seja: “esse objeto não funciona jamais como um significante na cadeia” (DIAZ ROMERO, 1997, p.42).

Este autor se pergunta: o que o analista poderia fazer diante destes casos em que o objeto, animal ou coisa (jamais um semelhante, pois neste caso o objeto fobígeno nos apontaria para uma estrutura histérica) insiste em ser posto à frente do paciente a cada vez que algo se apresenta como furo na imagem? Diaz Romero recorre à "função de tela", conceito desenvolvido por Lacan em seu seminário de 1964. A função de tela nos serve de suporte da significância, possibilitando ao neurótico uma rápida passagem do "instante do olhar" ao "tempo de com- 
preender". A hipótese de Diaz Romero é que para o sujeito fóbico esta função de tela não estaria constituída. A cada vez que estes têm que constituir a função de tela "eles o fazem jogando fora, colocando à frente de si um objeto qualquer e singular para poder ser” (DIAZ ROMERO, 1997, p.59). Não conseguir arranjar uma solução deste tipo leva a uma "perda dos sentidos”, um deixar de ser.

Para suprir a função de tela, para lhe possibilitar certa estabilidade, o fóbico tece uma malha, mas esta não apresenta a materialidade do interpretável, ou seja, não tem a materialidade do significante. Para este autor, as frases que constituem a malha apresentam uma pura materialidade combinatória, como se os recursos da palavra fossem reduzidos à função de signos.

Ao ouvir uma fala fora do registro do simbólico, a associação à psicose é imediata, mas Diaz Romero nos adverte que não é disto que se trata. A diferença é que a suplência da "função de tela" chegaria ao fóbico “desse limite entre o sujeito e o mundo" (idem, p.61) e não da impossibilidade de ter corpo. Quanto à direção da cura, ao se ver diante do não interpretável, restaria ao analista, a partir do lugar da voz, ou do lugar do olhar, “constituir um 'perceptum' que seja causa da organização da tela” (idem, p.63).

Se Lacan se atém ao paradigma representado pelo caso do pequeno Hans, Diaz Romero vai além. Ao fazer sua aproximação à problemática apresentada pela fobia pelo viés da relação de objeto, Lacan aponta-nos, em seu seminário de 1956-57, que "se tomarmos a coisa na perspectiva da relação de objeto, o fetiche desempenha, na teoria analítica, uma função de proteção contra a angústia e, coisa curiosa, a mesma angústia, isto é, a angústia de castração” (LACAN, 1956-57/1995, p.22). Ele nos adverte de que não é pelo mesmo viés que o fetiche e o objeto fóbico se ligam à angústia de castração, mas logo adiante coloca que "não (podemos) deixar de ver que, também aqui, (no fetiche), o objeto tem certa função de complementação com relação a alguma coisa que se apresenta como um furo, até mesmo como um abismo na realidade" (LACAN, 1956-57/1995, p.22).

Ao conceber a fobia em termos de um momento de passagem (momento lógico, que nada diz da duração cronológica do episódio fóbico), assim como uma placa giratória que também realizaria a junção das duas grandes ordens da neurose com a estrutura perversa, Lacan parece nos apontar para pontos de proximidade da fobia com a perversão. Já, ao conceber um segundo grupo para as fobias em que teríamos a construção de uma suplência à função de tela, Diaz Romero aproxima as fobias também à psicose, apesar de nos advertir de que não se trata da mesma coisa. Ao mesmo tempo, confere a este segundo grupo de fobias uma estabilidade que o autoriza a designá-las de estrutura diferencial.

Charles Melman, por sua vez, se propõe a elaborar as questões postas pela clínica das fobias apoiando-se no nó borromeu, último modo de escrita em- 
preendido por Lacan, a partir de 1972, para representar a estrutura do sujeito. Ao propor um anodamento borromeano diferenciado para as fobias em relação ao proposto por Lacan para as neuroses, Melman, a nosso ver, também aponta em direção a uma entidade clínica própria para as fobias, dotada de estabilidade e, como veremos, do mesmo modo que Diaz Romero, aproxima a fobia das psicoses.

Melman inicia sua elaboração isolando duas características de sua escuta de pacientes fóbicos: seu modo de relação com seu "acompanhante”, este duplo tão procurado e tão necessário à sua estabilização ao possibilitar que o fóbico se situe a partir da imagem do semelhante; e o efeito de paralisia sofrido pelo fóbico quando confrontado com o objeto fobígeno.

Segundo Melman: “O que provoca no fóbico seu acesso de angústia é um lugar disposto de tal forma que o que se encontra presentificado ali é tanto o buraco quanto algo que tem valor de olhar" (MELMAN, 1994, p.115). A necessidade que teria um sujeito de supor e eleger um objeto ou lugar que lhe presentifique o olhar nos diz que estamos diante de alguém cuja imagem de si próprio não está garantida em seu status imaginário-simbólico. Esta não garantia pode ser vista como indicativa de um tributo simbólico que não foi pago ao Outro.

Para Melman, com a invenção do animal fobígeno, o sujeito fóbico está a pagar um tributo ao Outro, mas este tributo não seria de ordem simbólica, mas sim de ordem imaginária. Nas fobias marcadas pela eleição de um objeto fóbígeno é como se em torno deste objeto houvesse uma zona mágica, espectro de um buraco desencadeador da angústia, a criatura fobígena vindo tamponar o Imaginário marcado pela dimensão do buraco da castração. No caso do agorafóbico, o pagamento viria em forma de uma amputação do espaço propriamente dito.

No nó borromeu característico da neurose, o círculo do Real passa por cima do Simbólico e, por fim, o círculo do Imaginário vem assegurar a consistência do nó passando por cima do Real e por baixo do Simbólico. Melman (1994, p.151) chama o nó resultante desta montagem de "dito 'normal"”. Este autor nos convida a pensar quais seriam as consequências se, no caso da fobia, o círculo do Real passasse por cima do Imaginário e, a partir daí, fosse o círculo do Simbólico que se achasse em posição de assegurar a consistência do nó.

“O que aparece na fobia é certamente uma relação singular entre imaginário e real: é de alguma forma o imaginário - contrariamente ao que acontece no nó dito 'normal' — que parece essencialmente marcado pela dimensão do buraco; neste dispositivo, nós temos o sentimento que a operação da castração se exerce no registro do imaginário, enquanto que no nó dito 'normal' a dimensão da castração é habitualmente mascarada pelo imaginário." (MELMAN, 1994, p.153) 
Lacan, ao discutir a saída atípica do pequeno Hans também coloca a castração, em Hans, incidindo no registro do Imaginário. Uma consequência da castração incidir no registro do imaginário é que a distância, dimensão pertencente a este registro, é que passa a modular a relação do sujeito com este representante fálico e não os recursos à metáfora e à metonímia, próprios do registro simbólico.

Se a estabilidade é um dos critérios para falarmos de estrutura, é digno de nota que encontramos existências perfeitamente organizadas em torno destas limitações impostas por tal amputação no registro do imaginário. Melman concebe os momentos em que o fóbico experimenta intensa angústia, como o que precede a eleição do objeto fobígeno; como se um dos três círculos, o do imaginário, se visse soprado. A consequente dissociação dos registros real e simbólico levaria a pensar em algo da ordem da psicose, mas Melman (1994, p.124) adverte: "não há psicose porque tudo leva a pensar que, para o fóbico, o recalque originário operou e que o Real e o Simbólico se mantêm perfeitamente”.

Se Diaz Romero vai além do paradigma que representa o caso do "pequeno Hans”, o mesmo não pode ser dito de Melman. Por outro lado, considerando que o nó borromeu é um modo de escrita que tem o intuito de representar a estrutura do sujeito, ao falar de uma estabilidade diferenciada alcançada pelo sujeito a partir de um episódio fóbico como o do “pequeno Hans”, e propor um anodamento borromeano diferenciado, Melman acaba também insinuando para o fóbico uma estrutura diferenciada em relação às duas grandes ordens da neurose.

\section{RETORNO AO CASO CLÍNICO}

A psicanálise, como constructo teórico, não apenas surge a partir da escuta clínica de Freud como somente mantém seu sentido no que continua a nos possibilitar tratar o real da clínica pelo simbólico. É no bojo deste movimento dialético que se insere nosso retorno ao caso clínico, uma vez tendo efetuado um percurso de investigação teórica a partir da interrogação sobre a possibilidade de tomar a fobia como uma entidade clínica. Neste percurso, identificamos a posição derradeira de Freud como sendo a de categorizar as fobias como histeria de angústia, a qual seria, então, a entidade clínica incluída entre as neuroses de transferência. Em Lacan, a afirmação mais categórica toma a fobia menos como uma entidade clínica isolável do que como uma figura clínica localizável em contextos diversos. Por fim, com Diaz Romero e Melman, autores lacanianos, verificamos ser postulado um estatuto estrutural para a fobia.

Constituído este panorama, passemos ao caso.

Professor em escolas de primeiro e segundo graus, o paciente já se encontrava em análise há certo tempo quando um aluno seu o ameaçou fisicamente. 
Por consequência, ele pediu para ser transferido de escola, no que foi atendido. Cerca de três meses após assumir as novas turmas, passou a sofrer de intensa fobia que resultou em afastamento de suas atividades profissionais. Seu objeto fobígeno: alunos, ou melhor, qualquer pessoa que ele identificasse como aluno, independentemente de sexo, idade ou do local onde ele viesse a se defrontar com seu objeto.

Rapidamente seu medo se intensificou. Ele agora não só adiava as saídas de seu apartamento, mas raras vezes saía dele. Com o passar do tempo, ele passou a se restringir à sala de seu apartamento, evitando a cozinha e seu quarto. Se antes o paciente tinha um ritual para dormir, agora evitava dormir no quarto, pois, quando apagava as luzes, “o chão e as paredes desapareciam”; ele ficava “suspenso em meio ao nada”! Quando era obrigado a sair do apartamento, com frequência sofria o que ele denominou de "apagão" — quando o paciente não conseguia se recordar do que fez durante várias horas, "acordava” não sabendo como chegou ao local onde se encontrava e sem noção do tempo transcorrido.

Ao longo das sessões, o paciente conseguiu isolar três eventos que desencadearam a fobia: 1) nos dias imediatamente anteriores a seu afastamento das aulas, uma parenta sua se hospedara em sua casa; o paciente sentia a presença desta parenta como um cerceamento de sua privacidade; 2) em uma aula, a partir do momento em que os alunos passaram a se engajar em brincadeiras (ou agressões) de claro cunho sexual, ele perdeu o controle da classe; 3) ao ser chamado de 'incompetente e mentiroso' por um senhor durante um evento escolar extraclasse, sentiu-se muito angustiado.

Já há vários meses em análise, o paciente revelou que durante a adolescência fora abusado sexualmente com regularidade por um parente. Apesar de este abuso ter perdurado por vários anos, ele afirmava repetidas vezes que nunca teria gostado do que este parente fazia com ele. Por outro lado, não havia deixado de considerar este parente um amigo.

Durante o ano seguinte, o paciente trabalhou muitos sonhos, contou à família do abuso sofrido e, por fim, iniciou um relacionamento. No entanto, este ano de trabalho não diminuiu seus medos: em determinada sessão, em que relatava mais uma vez as consequências de ele ter contado à família do abuso sofrido durante sua adolescência, o analista interveio: "Você sempre me disse que não gostava do que ele fazia...". Não era a primeira vez que o analista dissera algo semelhante, mas desta vez o paciente irrompeu em um choro intenso. Disse: "Eu não me lembrava disso! Só lembrava das vezes depois! As vezes em que eu dizia que não gostava do que ele fazia. Ai que nojo!” Esta reação remete às catarses relatadas nos primórdios da psicanálise. 
A fala do paciente denuncia que desta primeira vez foi diferente. Esta primeira vez foi anterior às vezes em que ele "não gostava". Ele acredita que esta cena antecedeu em alguns anos as antes relatadas.

Aproveitemos aqui para retomar a lógica do sintoma que nos é apresentada por Freud (1933 e 1937). Esta encontra seu primeiro tempo com a vivência pelo sujeito de uma cena traumática. Freud (1933) define o trauma como um momento vivido pelo sujeito que não pôde ser ligado pelas normas do princípio do prazer, um encontro direto do Eu com uma exigência libidinal excessiva. A angústia gerada nesse encontro provoca o recalcamento do representante da cena que resulta em uma desvinculação deste representante do afeto correspondente.

Em Análise terminável e interminável, Freud (1937) de início expressa a seguinte posição: para que venhamos a ter uma manifestação sintomática, faz-se necessária uma segunda vivência traumática. No decorrer do texto, ele amplia sua posição em relação a este segundo tempo de modo a incluir vivências que representem um enfraquecimento do Eu, como doença e esgotamento físico, assim como fortalecimentos pulsionais "por meio de novos traumas, imposição de frustrações e influências colaterais das pulsões entre si” (FREUD, 1937/1989, p.367). Ou seja, o sintoma irrompe nachträglich, em um segundo tempo. Para efeito da análise aqui empreendida, incluímos a vivência de uma cena que evoque a cena traumática entre os "fortalecimentos pulsionais".

No caso de uma fobia, "a angústia de castração recebe outro objeto e uma expressão transfigurada” (FREUD, 1926/1989, p.268) com as vantagens de oferecer um desvio do conflito de ambivalência e sua angústia ser facultativa, pois só aparece na presença do objeto. Ao discutir as condições para eleição do objeto fóbico, Freud (1909/1989, p.54) escreve: “a teoria exige que o mesmo que uma vez foi objeto de grande prazer, seja hoje objeto da fobia”.

O caso aqui apresentado parece reunir todos estes elementos. A "primeira vez" reúne todas as características de um momento traumático, inclusive sua expulsão da consciência. Até o momento em que o paciente rememora a cena traumática ele afirma, apesar de tudo, que este parente que dele abusou sexualmente era seu amigo. Já professor, este paciente se orgulhava de ser um professor "paizão": dar aulas era uma fonte de prazer. A ameaça sofrida não alterou sua relação com seus alunos. Somente depois, ao presenciar a brincadeira, um tanto agressiva, de cunho sexual de seus alunos é que temos a formação da fobia, a eleição do objeto fóbico por deslocamento. Uma cena que ao mesmo tempo que evoca a "primeira vez" o poupa da ambivalência em relação a seu parente.

Quanto aos demais elementos desencadeadores relatados pelo paciente, estes parecem apontar para ganhos secundários ou, seguindo o raciocínio de Freud (1937) acima exposto, para elementos enfraquecedores do Eu. Sob ambos os pontos de análise, afastado de suas atividades ele voltaria a gozar de um pouco 
de privacidade e não correria o risco de outra vez ser chamado de incompetente e mentiroso durante eventos escolares extraclasse. Tudo parece apontar para o diagnóstico de uma histeria de angústia, mas o real da clínica não se deixa tamponar com tanta facilidade: a fragilidade quanto ao registro do imaginário do paciente persiste.

Em uma de suas últimas sessões, antes de se mudar de cidade, o paciente relatou que, durante uma visita a um museu, uma das salas evocou a lembrança de um dos locais em que ele sofreu repetidos abusos. Ele passou a sentir-se angustiado e somente conseguiu se afastar deste ambiente que sente como tão ameaçador tirando fotos. Com os olhos fixos no visor da câmara fotográfica tirou cerca de seiscentas fotos até sentir que sua angústia cedeu. Era necessário o enquadre de cada imagem para que a dimensão do imaginário se sustentasse. Como nos diz Melman (1994): esta dimensão só se sustenta se a janela do imaginário se mantiver firme.

Este caso parece nos apontar duas direções distintas em relação à questão que nos move. A eleição do objeto fóbico parece ter obedecido à lógica do sintoma em Freud. Teríamos, assim, uma fobia de origem traumática que, como Freud nos diz, seria ligada à histeria: uma histeria de angústia inserida entre as neuroses de transferência, na estrutura neurótica. Na outra direção, a dos desfalecimentos (apagões), da amputação do espaço exemplificada no desaparecimento do chão do quarto, e da engenhosidade de emoldurar o visto como meio de mitigar a angústia, teríamos um traço diferencial, marcado por uma relação com a castração distinta da que encontramos entre as neuroses: uma castração simbólica evitada.

Não necessariamente estas duas direções para a apreensão deste caso de fobia são inconciliáveis. A princípio devemos colocar que, em comum, tanto nas duas grandes ordens da neurose, a histeria e a neurose obsessiva, quanto na fobia, o recalque primário operou de modo satisfatório. Assim, neste caso, podemos caracterizar a fobia por uma relação diferenciada da angústia de castração, nos moldes da "evitação" trabalhada por Lacan em relação ao "pequeno Hans", mas que não configura uma entidade clínica isolada, por dispor do recurso ao recalque. É o que nos parece atestar a formação de um sintoma no caso clínico que trouxemos.

Recebido em 31/5/2010. Aprovado em 31/8/2010. 


\section{REFERÊNCIAS}

DIAZ ROMERO, R. (1997). Fobias e melancolia — o que suas estruturas nos ensinam. Salvador: Máthesis.

DOR, J. (1994) Estruturas e clínica psicanalítica. Rio de Janeiro: Taurus.

FREUD, S. (1987) Edição standart das obras completas de Sigmund Freud. Rio de Janeiro: Imago Editora.

(1894) “As neuropsicoses de defesa”, v.III, p.51-65.

(1895a) “Obsessões e fobias”, v.III, p.73-83.

(1895b) "Sobre os fundamentos para destacar da neurastenia uma síndrome específica denominada 'neurose de angústia”, v.III, p.87-114.

(1895) "Resposta às críticas a meu artigo sobre a neurose de angústia”, v.III, 115-131.

FREUD, S. (1989) Sigmund Freud Studienausgabe. Frankfurt am Main: S. Fischer Verlag.

(1909) “Analyse der Phobie eines fünfjährigen Knaben”, v.VIII, p.9-124.

(1914). “Zur Einführung des Narzismuss”, Band. III, p.37-68.

(1915a) “Die Verdrängung”, Band. III, p.103-118.

(1915b) “Das Unbewusste”, Band. III, p.119-173.

(1917) “Vorlesungen zur Einführung in die Psychoanalyse - Die Angst”, Band. I, p.380-397.

(1926) “Hemmung, Symptom und Angst”, Band. VI, p.227-308.

(1933) "Neue Folge der Vorlesungen zur Einführung in die Psychoanalyse”, Band. I, p.448-608.

(1937) “Die endliche und die unendliche Analyse”, Ergänzungsband, p.331-392.

LACAN, J. (1945/1998) “O tempo lógico e a asserção de certeza antecipada”, in: Escritos. Rio de Janeiro: Jorge Zahar.

(1956-1957/1995) O seminário, Livro 4: A relação de objeto. Rio de Janeiro: Jorge Zahar.

(1957-1958/1999) O Seminário, Livro 5: As formações do inconsciente. Rio de Janeiro: Jorge Zahar.

. (1962-1963/1997) A angústia, seminário 1962-1963. Recife: Centro de Estudos Freudianos do Recife.

. (1963-1964/1998) O seminário, Livro 11: Os quatro conceitos fundamentais da psicanálise. Rio de Janeiro: Jorge Zahar.

(1968-1969/2008) O seminário, Livro 16: De um Outro ao outro. Rio de Janeiro: Jorge Zahar.

(1969-1970/1992) O seminário, Livro 17: O avesso da psicanálise. Rio de Janeiro: Jorge Zahar.

MELMAN, C. (1994) "O nó borromeu na fobia”, in: CALLIGARIS, C., DEPUIS, R., HILTENBRAND, J.P., LACOTE, C., VANDERMERSCH, B. (Orgs.). A fobia. Rio de Janeiro: Revinter. (Coleção Trimestre Psicanalítico) 
MELMAN, Charles. (1994) "O nó fóbico". In: CALLIGARIS, C., DEPUIS, R., HILTENBRAND, J.P., LACOTE, C., VANDERMERSCH, B. (Orgs.). A fobia. Rio de Janeiro: Revinter, 1994. (Coleção Trimestre Psicanalítico)

MILLER, J. A. (1995) A lógica na direção da cura. Belo Horizonte: Escola Brasileira de Psicanálise do Campo Freudiano.

André Ehrlich

andreehrlich@gmail.com

Vinicius Anciaes Darriba

vdarriba@centroin.com.br 